\title{
Experimental investigation of the aerodynamics of a large industrial building with parapet
}

\author{
Aly Mousaad Aly ${ }^{*}$ (D), Matthew Thomas and Hamzeh Gol-Zaroudi
}

\author{
* Correspondence: aly@lsu.edu \\ Windstorm Impact, Science and \\ Engineering (WISE) Laboratory, \\ Department of Civil and \\ Environmental Engineering, College \\ of Engineering, Louisiana State \\ University, 3230H Patrick F. Taylor \\ Hall, Baton Rouge, LA 70803, USA
}

\begin{abstract}
The aerodynamic performance of a roof depends significantly on its shape and size, among other factors. For instance, large roofs of industrial low-rise buildings may behave differently compared to those of residential homes. The main objective of this study is to experimentally investigate how perimeter solid parapets can alter the flow pattern around a low-rise building with a large aspect ratio of width/height of about 7.6, the case of industrial buildings/shopping centers. Solid parapets of varied sizes are added to the roof and tested in an open-jet simulator in a comparative study to understand their impact on roof pressure coefficients. Roof pressures were measured in the laboratory for cases with and without parapets under different wind direction angles (representative of straight-line winds under open terrain conditions). The results show that using a parapet can alter wind pressures on large roofs. Parapets can modify the flow pattern around buildings and change the mean and peak pressures. The mean pressure pattern shows a reduction in the length of the separation bubble due to the parapet. The parapet of $14 \%$ of the building's roof height is the most efficient at reducing mean and peak pressures compared to other parapet heights.
\end{abstract}

Keywords: Aerodynamics, Open-jet testing, Turbulence, Pressure measurement, Lowrise buildings, Parapet

\section{Introduction}

\subsection{Background}

The aerodynamic problem of buildings and other bluff bodies presents a real challenge compared to streamlined bodies $[1,2]$. This is because bluff bodies are associated with flow separation that makes direct experimental testing and numerical solution indispensable for the understanding of the physics and the evaluation of the flow-induced forces [3-7]. In a summary of natural hazards compiled by the National Weather Service and the National Climatic Data Center, high-intensity winds amounted to significant total property damage [8]. In the United States, $70 \%$ of the buildings are classified as low-rise, either as residential or industrial and constitute most of the reported wind damage [9]. Since 1980, the frequency of billion-dollar climate events has increased.

(c) The Author(s). 2021 Open Access This article is licensed under a Creative Commons Attribution 4.0 International License, which permits use, sharing, adaptation, distribution and reproduction in any medium or format, as long as you give appropriate credit to the original author(s) and the source, provide a link to the Creative Commons licence, and indicate if changes were made. The images or other third party material in this article are included in the article's Creative Commons licence, unless indicated otherwise in a credit line to the material. If material is not included in the article's Creative Commons licence and your intended use is not permitted by statutory regulation or exceeds the permitted use, you will need to obtain permission directly from the copyright holder. To view a copy of this licence, visit http://creativecommons.org/licenses/by/4.0/. 
The majority of these events occur in the coastal areas with the bulk occurring in the southeast [10].

The roof components and claddings of low-rise buildings can be subject to damage during windstorms due to fluctuating pressures. These pressures can cause serious problems to the integrity of low-rise buildings, such as residential homes, large industrial buildings, and shopping centers. For instance, a roof failure due to high uplift wind forces was reported, due to high-intensity wind from Hurricane Charley [11]. Over 40\% of the membrane covering the gymnasium roof was detached during the storm when about four hundred people were sheltered in the building. As the frequency of windrelated failures increases, the need for wind resilient structures and non-intrusive wind mitigation devices becomes indispensable [12]. For purposes of sustainability, economic efficiency, and alleviation of wind issues, wind engineering research is vital to current and future development around the globe.

\subsection{Increased windstorm activity}

The increase in high climatic events can be attributed to the warming trends experienced globally. In a statistical investigation, it was found that between 1959 and 2002 the average atmospheric temperature increased by nearly 0.73 degrees Celsius [13]. Warming of the sea surface supplies the atmosphere with more water vapor, consequently more moisture for storms [14]. This increase in storms equates to an increase in the probability of wind-related damage occurring to low-rise structures. Although more studies and stronger evidence are needed to prove the validity of the predicted trends, it is safe to say that wind-related research is necessary for the present. As of September 2017, estimated damage of about $\$ 190$ billion would rank Hurricane Harvey as the costliest hurricane to hit the United States on record. Recent storms dominate the list of most costly hurricanes with Hurricane Katrina (2005) and Hurricane Sandy (2012) rounding up the top three. In fact, nine to ten of the most costly hurricanes to make landfall in the United States have come from the twenty-first century [15]. It is stated that the ten most expensive hurricanes in United States history occurred in the past 30 years. This may be attributed to climate change [16]. The impacts from climate change are happening now, affecting ecosystems and communities [17]. The 2017 Atlantic hurricane season was extremely active with six major hurricanes. El Niño-Southern Oscillation, the North Atlantic Oscillation, and the Atlantic Meridional Mode all contributed to favorable wind shear conditions. The Atlantic Meridional Mode also produced enhanced atmospheric instability [18].

In the town of Rockport, TX, where Harvey's eyewall made landfall, wind peaks of $130 \mathrm{mph}$ were recorded. Structural damage to homes and buildings was very widespread, as winds stripped walls and roofs lifted off of structures. The powerful hurricane ripped apart public infrastructure like the Rockport-Fulton High School [19]. Category five Hurricane Irma reached max sustained winds of $185 \mathrm{mph}$ as it hammered the small island of Barbuda on September 5, 2017. The storm damaged nearly every structure on the island and left $60 \%$ of them uninhabitable. Figure 1 shows roof damage caused by Irma's high winds on the island of Saint Martin [20]. The necessity for wind resilient structures is not only fundamental for the sustainability of future communities but the integrity of today's communities as well. The recent surge in high wind-related 


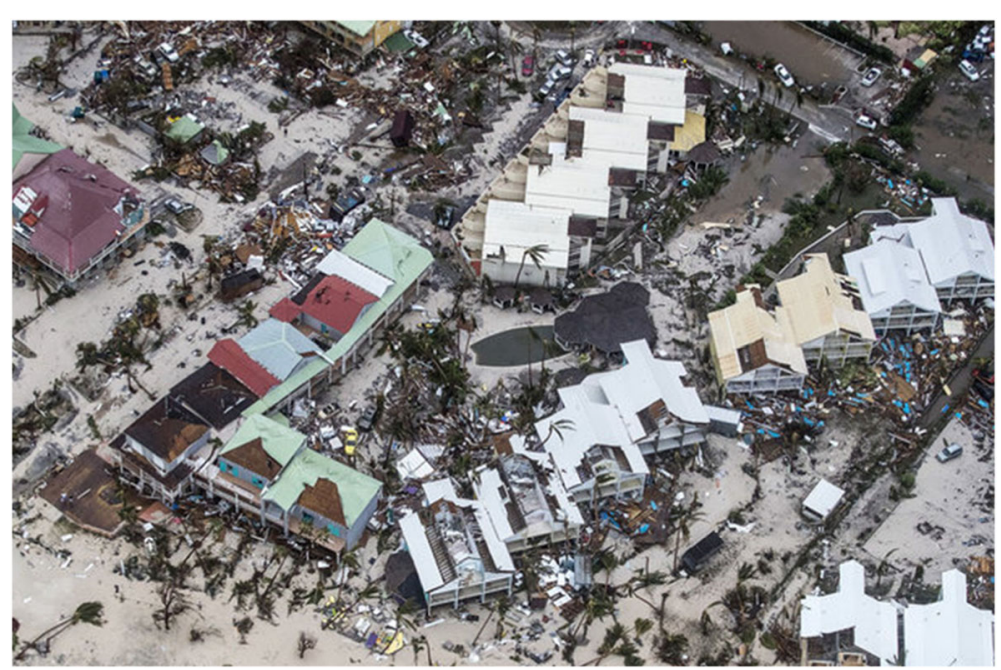

Fig. 1 Wind-induced damage from Hurricane Irma [20]

weather events justifies the need for extensive research on windstorm mitigation techniques.

\subsection{Aerodynamic testing}

In order to propose mitigation alternatives to minimize damage, it is vital to understand how the spatial correlation of wind loading influences the performance of the roof. As the first step to answer this question, the true reproduction of flow characteristics in accordance with actual windstorms is necessary. Bluff body aerodynamics and in particular the fluctuations of wind pressures on low-rise buildings have a complex spatial and temporal structure [21]. This complexity mainly comes from the transient nature of incident turbulent winds, and the fluctuating flow pattern in the separation zone. One main part of any wind engineering study is to appropriately reproduce the flow characteristics in a controlled manner, in order to examine the response of a structure in the scope of a particular windstorm. This means that the wind flow should be reproduced in an acceptable approach, and then wind pressures and loads on the structure should be validated accordingly. In order to satisfy these requirements, there are some common tools used for wind simulation, including wind tunnels, computational fluid dynamics (CFD) models, open-jet facilities, and full-scale field measurements [22].

Since the past decades, wind tunnel modeling has been widely used as a useful technique to estimate wind loads on buildings and other structures [23]. In the case of lowrise buildings, it has been always a challenge in wind tunnel testing to properly reproduce wind effects, due to the lack of capability in turbulence modeling [22]. Small-scale turbulence leading to the shedding of immature vortices is one of the reasons for inaccurate pressure estimations in wind tunnels. Full-scale experiments are economically expensive and difficult to control [24]. Full-scale CFD simulations are computationally demanding. The pros and cons of experimental and CFD techniques are identified in the first author's previous publications [22, 25]. The challenges in wind engineering testing and the importance of generating correct turbulence are pointed out in several 
studies [25-28]. To alleviate these issues, the concept of open-jet testing was devised recently [29].

In line with this, the Windstorm Impact, Science and Engineering (WISE) research team at Louisiana State University (LSU) built a small-scale open-jet wind engineering testing facility in 2014. The small-scale open-jet was calibrated to generate wind that mimics those of wind open and suburban terrain [29, 30]. With an adjustable turbulence producer, different wind profiles can be physically simulated. A multidisciplinary LSU research team from Civil Engineering, Mechanical Engineering, Coast \& Environment, Louisiana Sea Grant, Geography and Anthropology, Construction Management, and Sociology, collaborated on a project 'Hurricane Flow Generation at High Reynolds Number for Testing Energy and Coastal Infrastructure' that was awarded by the Louisiana Board of Regents to build Phase 1 of a large windstorm testing facility. Phase 1 permits the generation of wind flow at a relatively high Reynolds number over a test section of $4 \mathrm{~m} \times 4 \mathrm{~m}$. These capabilities permit executing wind engineering experiments at relatively large scales [31]. The modern open-jet facility will enable researchers from LSU and the globe to test their research ideas, to advance knowledge leading to innovations and discovery in science, hurricane engineering, and materials and structures disciplines, to build a more resilient and sustainable infrastructure.

\subsection{Aims of the current study}

While parapets can offer aesthetic features of a building - by creating architectural elements, hiding rooftop equipment, and serving other functions, they can act as an aerodynamic mitigation device. When designed with a proper height, parapet walls can minimize the magnitude of roof negative pressures [32, 33]. The effects of parapets on roof wind loads have been explored in past studies, however, there is a lack of agreement on their effectiveness in reducing the magnitude of roof pressures. The efficacy of a parapet in reducing the magnitude of wind pressures highly depends on its height, wind direction angle, and building's shape, among other factors [34-36]. In the real world, designing and installing parapets on roofs require an understanding of aerodynamics in a wind flow that mimics those at full scale. This is to ascertain the mitigation feature will function properly; otherwise, immature installation of mitigation features may cause additional problems to the roof's integrity during severe windstorms. This research adds to previous works on roof passive mitigation techniques, by further investigating the performance of parapets in advanced open-jet flow at a larger scale. The case study low-rise building has a large aspect ratio of width to height of 7.6. This is a representation of large industrial buildings and shopping centers. Parapets with varying heights are tested to find the best height to minimize uplift forces produced by high-intensity winds. The idea is to understand the performance of parapets as effective mitigation alternatives that are practical and economical and can reduce peak pressures at the roof corners and edges. The importance of the current study is that parapets and other architectural features are difficult to be tested in a typical wallbounded wind tunnel, due to blockage effects and scale issues.

The paper is structured as follows. In Section 2, a brief review of wind impact on the roofs of low-rise buildings and aerodynamic mitigation methods are presented. The methodology of the current study, including aerodynamic testing, is presented in 
Section 3. The results of the current study are discussed in Section 4. Section 5 summarizes the main findings.

\section{Brief review of wind effects on roofs and aerodynamic mitigation}

\subsection{Wind effects on low-rise buildings}

In 1963, 300 scientists and engineers from 21 different countries gathered at the National Physical Laboratory, Teddington, for an International Conference on Wind Effects on Buildings and Structures [37]. The conference was the first major attempt to bring together the researchers and practicing engineers in the field of wind engineering, in view of the extent to which the safe and economic design of all forms of building and structure is dependent on a proper understanding of the effects of wind. Most of the papers presented were concerned with the wide range of research throughout the world, and much reference was made to the use of wind tunnel testing as the main source of information. Up to date, experimental wind engineering is still the most accurate and reliable source of information.

When wind flows over the roof of a low-rise building, the flow eventually separates from the surface causing changes in pressures. In the early 1970s, the Aylesbury Experiment concluded that the highest pressures occur where the flow separates from the structure near the roof eaves, ridge, and corners. The experiment also highlighted that wind pressures typically fluctuate due to vortex shedding and other unsteady flow singularities [38]. The flow pattern around structures is greatly influenced by separation. Flow separation zones develop on the leeward side of roofs [39]. In the 1980s, a Texas Tech University (TTU) field experiment was conducted on a low-rise building with a nearly flat roof. Significant changes in pressures were realized at the leading corner, under the 45 deg. wind direction angle (conical vortices) [38]. These pressure gradients cause separation of the boundary layer and a formation of vortex flow that can produce uplift forces leading to cladding failure [40]. The vortex generation in the separated shear layer is associated with peak pressures [41]. Negative pressures are higher under the conical vertices. The peak suction is beneath the vortex core and moves as the vortex moves. In smooth flow, as the vortex size decreases, the peak suction increases linearly [42]. There is a direct correlation between the increasing speed of the vortex and the decrease in pressures experienced at the surface. Upstream flow and low pressures are connected in three main ways. First, the flow velocity normal to the roof's surface directly affects the speed of the vortex spin. Second, the pressure above the vortex will also be governed by the speed of the gust passing over the roof corner. Third, the strength of the vortex is related to the nature of the re-attachment [43]. The fluctuation in the uplift pressures is caused by the sway and rotation of the axes of the conical vortices [44]. The conical vortices generally occur in pairs, along each roof edge and normally with different circulating strengths [45]. The rotation and swaying of the axes induce fluctuations in the higher and lower frequency ranges [44]. Understanding these relationships and designing roof mitigation devices to combat the effects is vital to the durability of low-rise buildings.

Roof failure occurs when the roof can no longer support the wind-induced loading caused by varying pressures. Multiple studies have found that uplift forces from pressure variations put stress on the structure and can cause failure [43, 44, 46]. Failure of 
the roof sets off a domino effect resulting in the cascade failure of the whole building envelope. Once the roof is damaged, wind and rain are allowed to further damage the structure and the people inside [47]. Protecting the roofs of buildings is a viable solution to mitigate damage [48]. Innovative devices that solve this problem as well as adhere to economic, sustainability, and safety restraints can improve our communities' longevity and attest to the resiliency of humanity to natural disasters.

\subsection{Aerodynamic mitigation}

Low-rise buildings are commonly used all over the world for commercial, industrial, and residential purposes. The roof geometry used to cover low-rise buildings can greatly influence the aerodynamic pressures. Roof systems are subjected to higher loading than any other part of the structure [9]. While numerous studies and past experiences have shown that flat roofs are not the most efficient design, in terms of minimizing wind forces, they are found on the majority of low-rise industrial and commercial structures [49]. A reasonable solution to reduce the wind uplift forces is to utilize/implement simple modifications that change the flow pattern and impede the formation of vortices. These modifications usually focus on eliminating the sharp edges to reduce separation and disrupt the formation of vortices [50].

\subsubsection{Roof modifications}

One approach to roof modification considered the change of elevation [51]. Pressure coefficients were measured to assess whether or not they are affected by the variation of roof height. A minimal decreasing trend was found as the height of the roof was increased. However, it was concluded that pressure coefficients are independent of roof elevation [51]. Nevertheless, varying the pitch angle has some measurable changes. The roof pitch of 3:10 experienced negative pressures along the majority of its windward side [52]. The building with a pitch of 7.5:10 showed positive pressures along its windward side, with a significant reduction in the uplift forces. This roof configuration decreased the areas of turbulent kinetic energy experienced on the eave while showing increases in the shear layer beyond the rooftop [52]. Various architectural details were tested on low-rise structures with gable roofs. The mean pressures were reduced for buildings with protruding gable walls and eave gutters [53]. Buildings with architectural elements like gable end and ridgeline extensions, trellis, and wall extensions all experienced reductions in pressure coefficients [54]. Simple modifications and roof designs can alter the flow pattern thus reducing the negative pressures on the roof. Installing parapets has been the standard architectural modification used to mitigate wind effects on flat roofs.

\subsubsection{Parapets}

Numerous methods have been proposed and tested to change the geometry of the roof without fundamentally changing the design of the structure. Several mitigation features can reduce the intensity of corner pressures as follows: (1) features that displace the corner vortices (solid parapets can raise the vortices from the roof surface), (2) features that disrupt the formation of vortices (partial or porous parapets), and (3) features that disturb the vortices on the rooftop (a fence or object along the path of vortex 
formation) [46]. Figure 2 shows various aerodynamic mitigation schemes for reducing wind loads on roofs of low-rise buildings [50].

The addition of a perimeter parapet reduces the pressure coefficients in the corner zones by about 50\% [33]. The effectiveness of a parapet is directly correlated to its configuration. A parapet that covers the entire roof perimeter is more effective than a parapet that only protects one side of the building [50]. A series of comprehensive studies were conducted to examine the major effects of parapets on low-rise buildings [34-36, 55]. Reductions of corner pressure coefficients of $44 \%$ and $56 \%$ were recorded with the addition of spoilers and porous continuous parapets, respectively. A solid parapet only present at the corners caused a reduction in loads in all roof zones, compared to a solid continuous parapet [55]. When varying shaped parapets were added to a flat roof, a notable reduction in the lift forces was reported [56].

A parapet can reduce wind loads at the corners while it distributes the loads to interior regions [45]. Pressures measured on open canopy structures with parapets reveal that the parapet height is a key parameter. In general, reduced pressure coefficients are associated with higher parapets, while lower parapets increased the peak suction, compared to a bare roof [57]. During Hurricane Charley, low-rise buildings with high parapets survived with no damage on the roof edges and corners [11]. However, some of the air-handling units on the roofs of these buildings were lifted as they were not properly secured. These events demonstrate the motivation for research on the feasibility of devising aerodynamic features to reduce wind loads on the entire roof, to alleviate such issues with rooftop equipment and fatalities.

\section{Experimental investigations}

\subsection{Open-jet testing}

As mentioned earlier, the aim of this study is to experimentally examine the performance of solid parapets in reducing the aerodynamic loads on roofs of low-rise buildings (Fig. 3). Experimental investigations were conducted on a small-scale model of a lowrise industrial building in an open-jet hurricane simulator. The open-jet was validated in terms of flow quality [29], and then various aerodynamic tests were performed on the model with sets of parapets and without a parapet. Figure 4 represents the concept of open-jet testing. The open-jet was made from simple components, i.e., speed

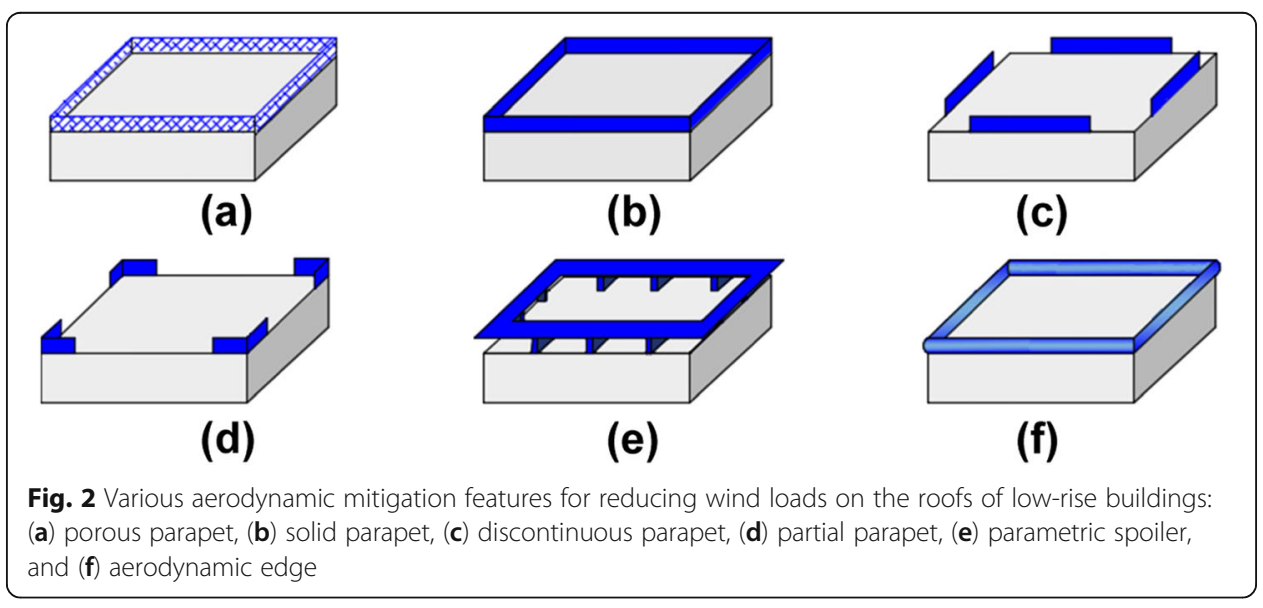




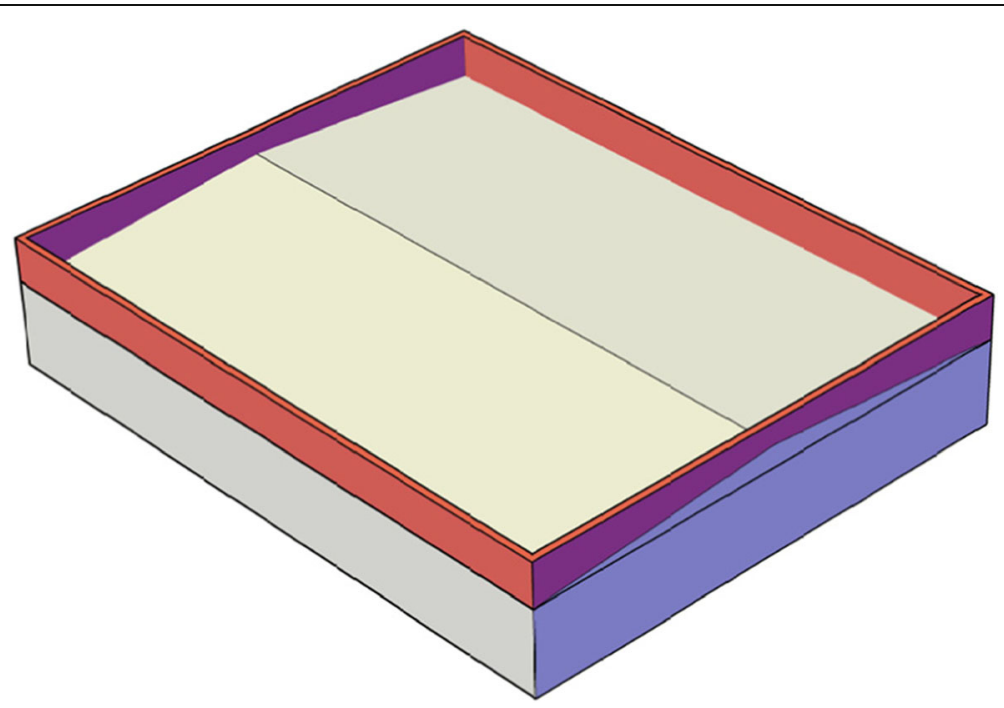

Fig. 3 The solid parapet on the roof of the low-rise building model

controller, fans, turbulence producer, etc. It consists of 15 fans in a $3 \times 5$ array. The small-scale open-jet has a test section of around $1 \mathrm{~m}$ in height and $1.7 \mathrm{~m}$ in width, and can produce a flow with a wind speed of up to $15 \mathrm{~m} / \mathrm{s}$. Using the adjustable turbulence production mechanism, it is possible to generate different wind speed profiles following a desirable terrain characteristic. More details regarding the flow management setup and validations of the LSU small-scale open-jet are available in previous publications $[29,30]$. The open-jet is capable of producing comparable mean wind speed and turbulence profiles to those at full-scale. Models with high blockage ratios were found to be feasible in the open-jet, highlighting its ability to reduce the effects of blockage on experimental data. In addition, the proximity of the test model to the open-jet affects the peak pressure measurements due to the varying length of the separation bubble. The closer the model was from the open-jet fans, the smaller the separation bubble. This is due to the increasingly high presence of small-scale turbulence close to the exit of the open jet. Therefore, the test model should be positioned at a recommended distance from the exit of the open-jet. This distance is approximately $2.5 \mathrm{H}$, where $\mathrm{H}$ is the

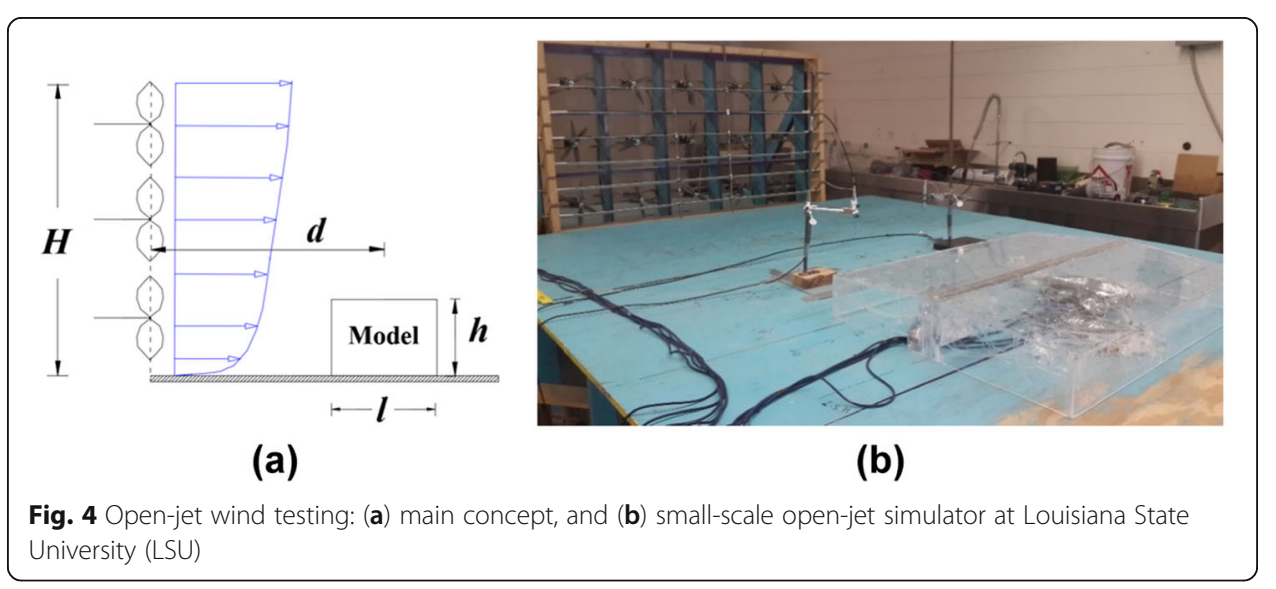


height of the wind field. After all data considered, the facility was found to be a viable option to reproduce aerodynamic pressure coefficients on buildings [29, 30].

\subsection{Experimental setup}

An actual industrial low-rise building, located in Louisiana, was modeled to investigate the aerodynamics characteristics of adding parapets to the roof. The building is shown in Fig. 5, which is a gable roof building with a large aspect ratio of $\sim 7.6$. The low-rise building has a gable roof with a slope of about $7 \mathrm{deg}$. A small-scale model was fabricated according to the characteristics listed in Table 1. To capture the best possible overall wind pressure distribution over the roof surface, a strategic and unique tap layout was chosen. This nonuniform distribution consists of 196 pressure taps with higher densities located at the corner, edges, and ridge (Fig. 6). Clusters of taps are located on the roof corners and edges as these locations experience the greatest variability in aerodynamic pressures. These individual taps monitor the instantaneous time-varying surface pressures to form a global roof pressure distribution. The wind direction angle is measured from the axis orthogonal to the smallest plan direction in a counterclockwise (Fig. 6). The test wind direction angles were chosen to ascertain the dominant pressure distributions. Due to its symmetry, only the following wind direction angles were deemed necessary: 0,45 , and 90 deg.

The small-scale model is made of $5 \mathrm{~mm}$ thick sheets of acrylic plastic (Fig. 7). The pressure taps were connected to Scanivalve scanners using $550 \mathrm{~mm}$ long flexible urethane tubing with a diameter of $1.37 \mathrm{~mm}$, acceptable for wind tunnel testing. The length of the tubes was chosen based on the guidelines published in a cooperative agreement between TTU and the National Institute of Standards and Technology (NIST) [23]. The transfer function of the tubes was considered, and the pressure data were corrected so that the length does not negatively affect the measured pressures [30]. The tubes are connected to ZOC miniature electronic pressure scanning modules that are specifically designed for wind tunnel testing where the pressures do not exceed 50 psi.

Fig. 7 shows the experimental setup. One crucial step in the data acquisition procedure was to make sure that the wind speed and wind direction were following the target ranges. This is more tangible if it is pointed out that time histories of pressure coefficient are directly dependent on the velocity measurements at a reference height.

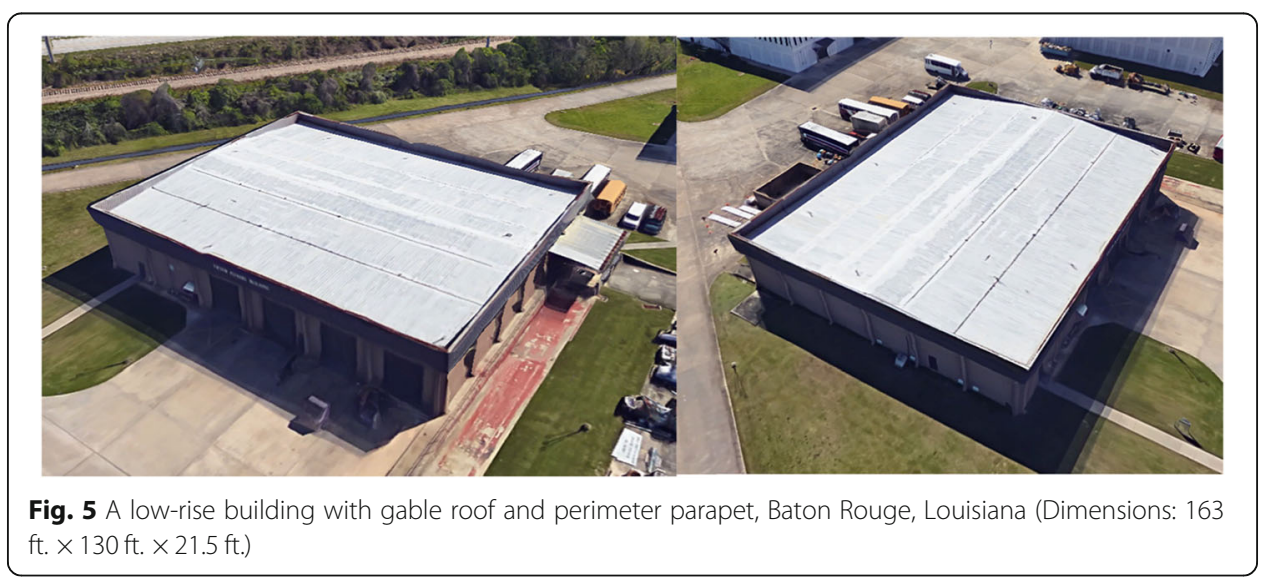


Table 1 Details of the building case study and the aerodynamic experiment

\begin{tabular}{|c|c|}
\hline Full-scale dimensions, $\mathrm{W} \times \mathrm{L}$ & $49.68 \mathrm{~m} \times 39.62 \mathrm{~m}(163 \mathrm{ft} . \times 130 \mathrm{ft})$. \\
\hline Eave height, $\mathrm{H}$ & $6.55 \mathrm{~m}(21.5 \mathrm{ft})$. \\
\hline Roof slope & 1 to 12 gable roof \\
\hline Real perimeter parapet height & $0.91 \mathrm{~m}(3 \mathrm{ft})$. \\
\hline Suggested perimeter parapet heights & $0,0.46,0.91,1.38$, and $1.83 \mathrm{~m}(0,1.5,3,4.5,6 \mathrm{ft})$. \\
\hline Number of pressure taps & 196 \\
\hline Model scale & 1:50 \\
\hline Model dimensions, $w \times 1 \times h$ & $99.36 \mathrm{~cm} \times 79.24 \mathrm{~cm} \times 13.1 \mathrm{~cm}$ \\
\hline Maximum open-jet blockage ratio & $8.51 \%$ \\
\hline Upstream terrain roughness, $z_{0}$ & $0.03 \mathrm{~m}$ (0.1 ft.) \\
\hline Wind direction angles & 0,45 , and 90 deg. \\
\hline
\end{tabular}
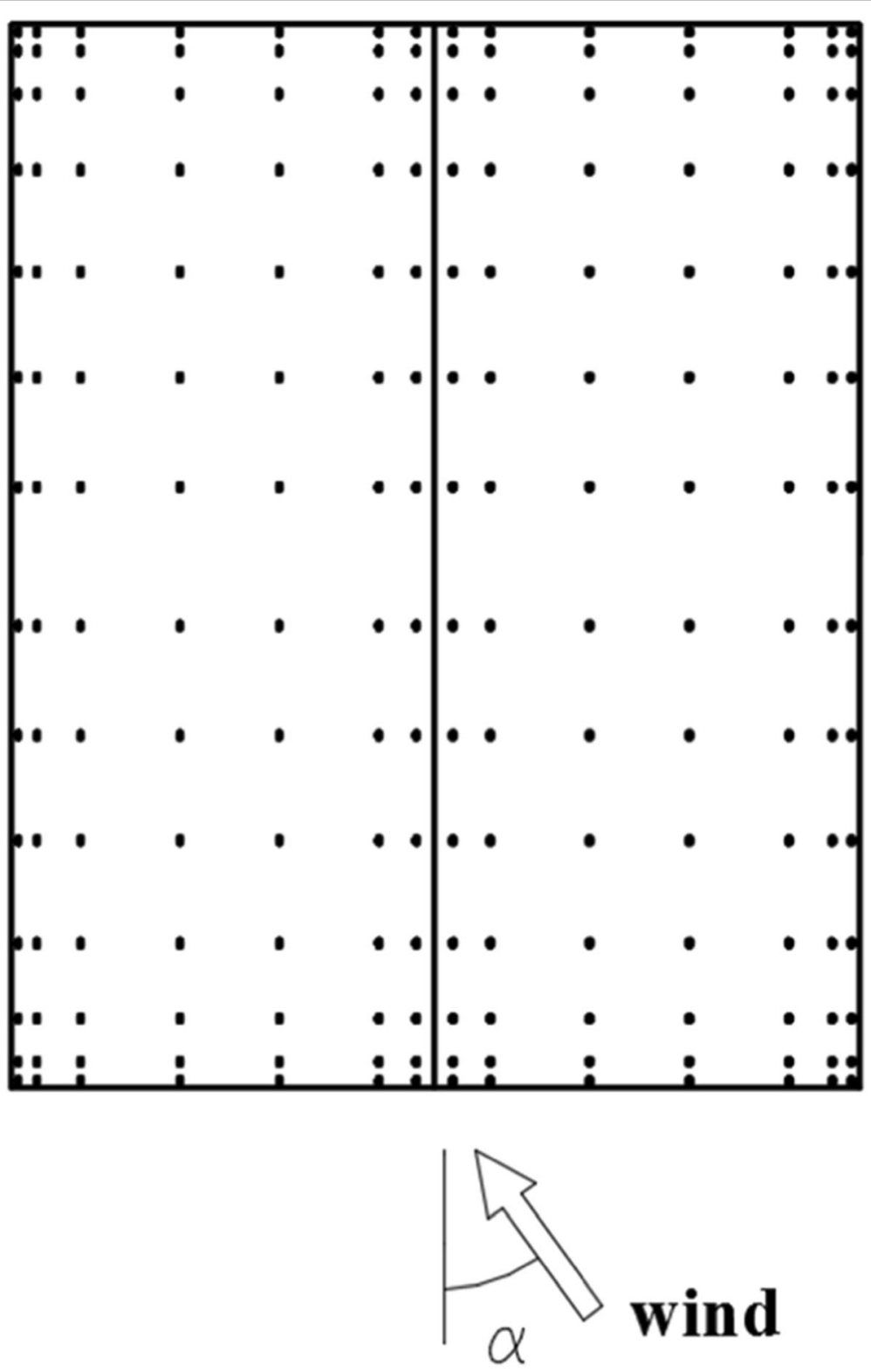

Fig. 6 Location of pressure taps, and definition of wind's angle of attack 


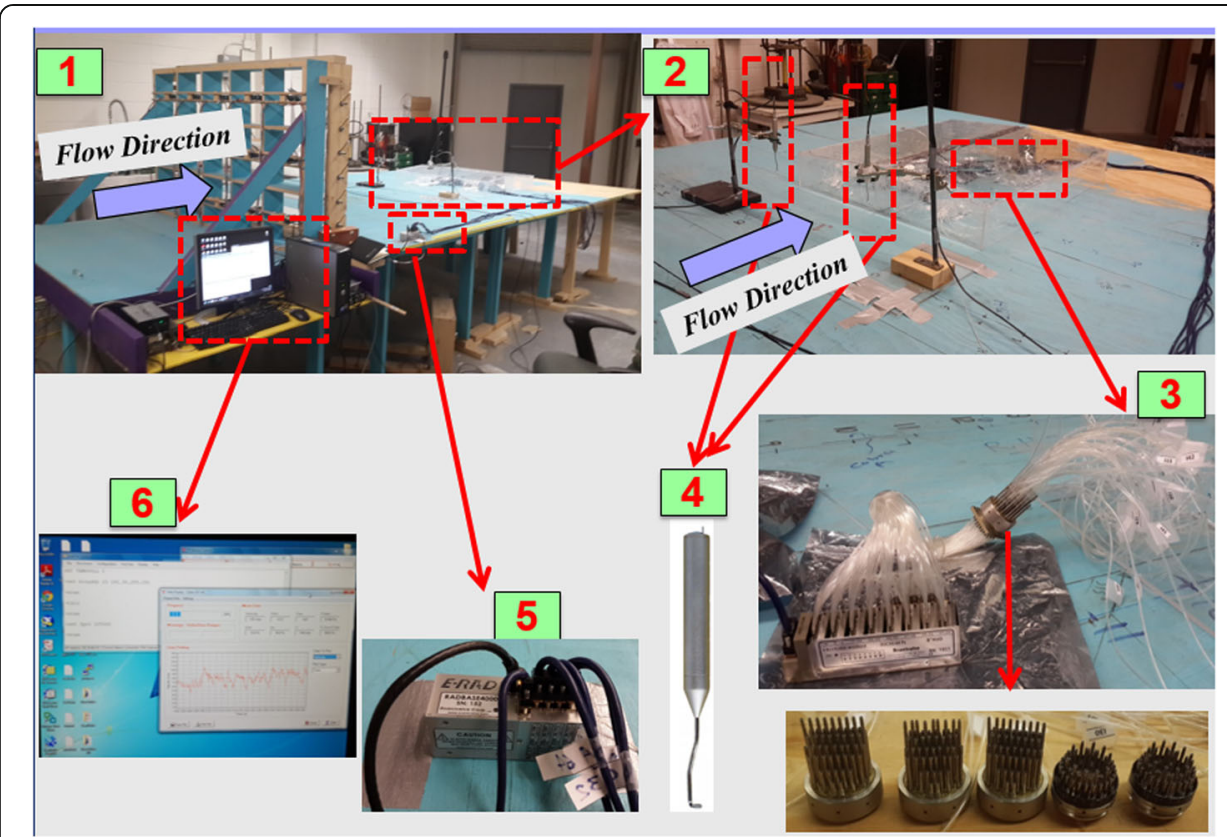

Fig. 7 Experimental setup: (1) general view of the open-jet simulator, (2) instrumented test model, (3) view of a pneumatic connector, (4) cobra probe, (5) ZOC miniature electronic pressure scanning module, and (6) instantaneously measured velocity

Therefore, wind speed measurements were performed using Cobra probes [58]. More details regarding the high-tech instruments that were used in the experiment are presented as follows. In Fig. 7, there are two Cobra probes used to monitor the free stream velocity at mean roof height. The Cobra probe is a multi-hole pressure probe that can measure time-varying three-components of flow velocity, pitch, and yaw angles, as well as the local static pressure in real-time [59]. Miniature pressure scanners were used in to measure aerodynamic pressures. Two types of compact pressure scanners were used: three from the ZOC33 series and one from the ZOC22b series [60]. The ZOC modules have been used in conjunction with RADBASE as shown in Fig. 7.

\subsection{Pressure measurements}

Pressure data were collected at a sampling rate of $625 \mathrm{~Hz}$. Each test on the 1:50 scale model was run for three minutes. The corresponding full-scale duration can be obtained as follows.

$$
\left(\frac{f l}{u}\right)_{m}=\left(\frac{f l}{u}\right)_{p}
$$

Where $f$ denotes the sampling frequency, $u$ defines the mean wind velocity at a reference height (roof mean height), and $l$ stands for a characteristic dimension of the structure. The subscripts $m$ and $p$ denotes 'model' and 'prototype', respectively. The reference full-scale wind velocity at a $10 \mathrm{~m}$ height is $17.8 \mathrm{~m} / \mathrm{s}$. The full-scale velocity at the roof height $(6.55 \mathrm{~m})$ is calculated as follows: $u_{p}=17.8(6.55 / 10)^{0.15}=16.71 \mathrm{~m} / \mathrm{s}$. Therefore, according to Eq. (1), $f_{m} / f_{p}=\left(u_{m} / u_{p}\right) \times\left(l_{p} / l_{m}\right)=(8 / 16.71) \times(50)=23.94$. This means that the corresponding full-scale duration is $3 \times 23.94=71.8 \mathrm{~min}$ (well above an hour). The time history of pressure coefficients was obtained from the measured pressures as follows. 


$$
C_{p}(t)=\frac{p(t)-\bar{p}_{s}}{(1 / 2) \rho U^{2}}
$$

Where $\rho$ is the air density, and $U$ stands for the mean wind speed measured at the reference height (roof height). The term $p(t)-\bar{p}_{s}$ defines the difference of instantaneous pressure to the mean static pressure.

After calculating the non-dimensional pressure coefficients, the peak values are extracted from the time series of pressure measurements, for each tap, by using an approach that accounts for the uncertainties in the estimation of peak values from a time record [61]. The approach accounts for the effects of time series duration and sampling frequency on the estimated peaks. The procedure most accurately extracts those peak values from the time history. Using a probabilistic approach, the appropriate marginal probability distribution of the time series was identified. Following this, the probability was used to estimate the distribution of the peaks using the standard translation processes approach. The peak values estimated using this procedure are less dependent on the variables - time duration and sampling frequency [61].

NIST published MATLAB functions for computing quantiles, or values corresponding to specified probabilities of non-exceedance, of the maximum and minimum input time series values [62]. These functions were used in the current study to evaluate the quantiles of the maximum and minimum time series values of peak pressure coefficients. More specifically, a 95\% quantile peak was estimated. With a $95 \%$ quantile, the estimated peak pressure value has a $5 \%$ probability of being exceeded. This means that the negative peak pressure coefficient has a $5 \%$ chance of being higher than the estimated value.

\section{Results and discussion}

In this section, the results of the pressure measurements are plotted in contours, over the roof surface of the test model. For each wind direction angle $(0,45$, and 90 deg.) and parapet height $(0 \mathrm{ft} .(0 \mathrm{~m}), 3 \mathrm{ft} .(0.914 \mathrm{~m}), 4.5 \mathrm{ft} .(1.372 \mathrm{~m})$, and $6 \mathrm{ft}$. $(1.829 \mathrm{~m})$ ), the contours are presented in terms of mean and peak pressure coefficients. The mean pressure coefficients are computed directly from averaging the measured data, while the peak pressure coefficients are estimated from the statistical approach described in Ref. [61]. Due to the fact that the peak values are derived from a statistical approach, comparing mean values is a concrete approach to understanding the effects that parapets have on the wind pressures on the roof. In the contour plots, the length and width dimensions of the model are normalized on each axis. The contour plots consider the mean and peak pressure coefficients from each individual tap.

Figure 8 shows the mean and 95\% peak pressure coefficients for the scaled model tested without a parapet under a wind direction angle of 0 deg. Similarly, Figs. 9, 10 and 11, show the contours for the mean and 95\% peak pressure coefficients for the scaled model tested under the 0 deg. wind direction fitted with $3 \mathrm{ft} .(0.914 \mathrm{~m})$, $4.5 \mathrm{ft}$. $(1.372 \mathrm{~m})$, and $6 \mathrm{ft}$. $(1.829 \mathrm{~m})$ equivalent parapets. For simplicity, the $95 \%$ peak pressure coefficients will be referred to as the peak value. The results show that the addition of a parapet does indeed change the roof's aerodynamics and 


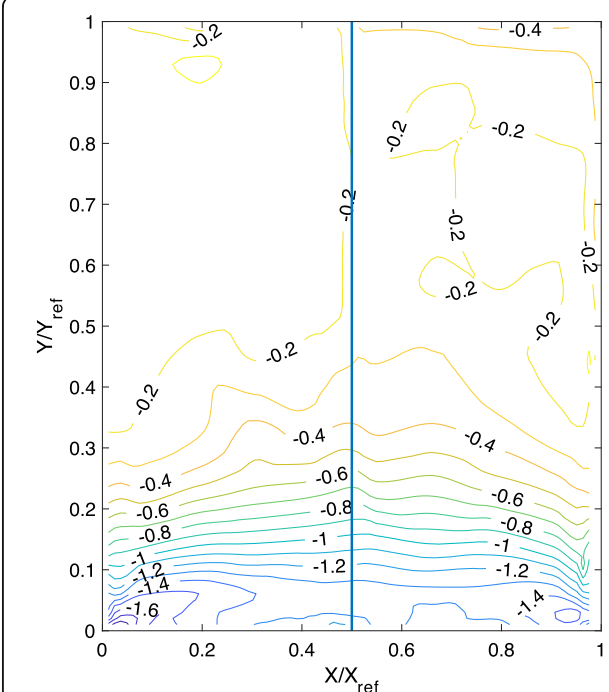

(a)

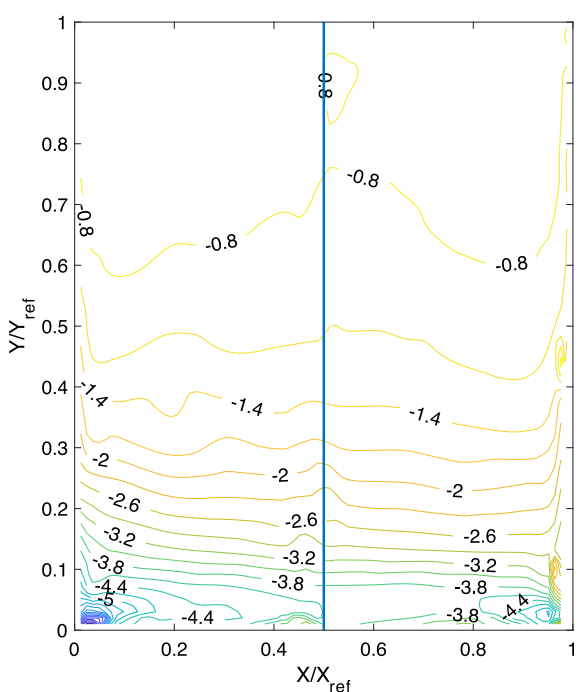

(b)

Fig. 8 Contours of roof pressure coefficients $(\theta=0$ deg.), for the no parapet case: (a) mean Cps, and (b) 95\% quantile peak Cps

consequently the mean and peak pressures. Under the 0 deg. wind direction with no parapet, the length of the separation bubble, or negative mean pressures cover the entire roof, indicating that the flow remained separated with no reattachment. It is worth to mention that, depending on the roof size, shape, wind speed (or Reynolds number), in flow turbulence, among other factors, the separated flow may reattach or may not. Flow reattachment can be realized by positive mean pressures on the roof with parapets. The flow separation is a complicated phenomenon in bluff body aerodynamics. In fact, this is where CFD simulations fail to yield accurate predictions of aerodynamic pressures,

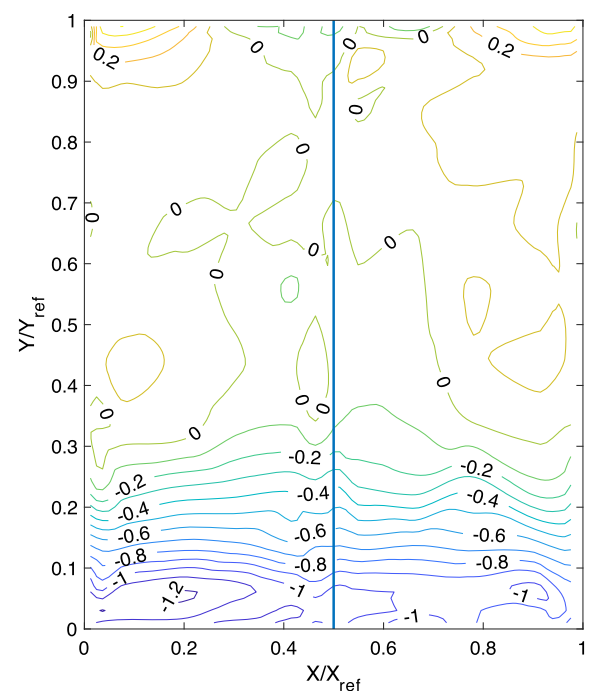

(a)

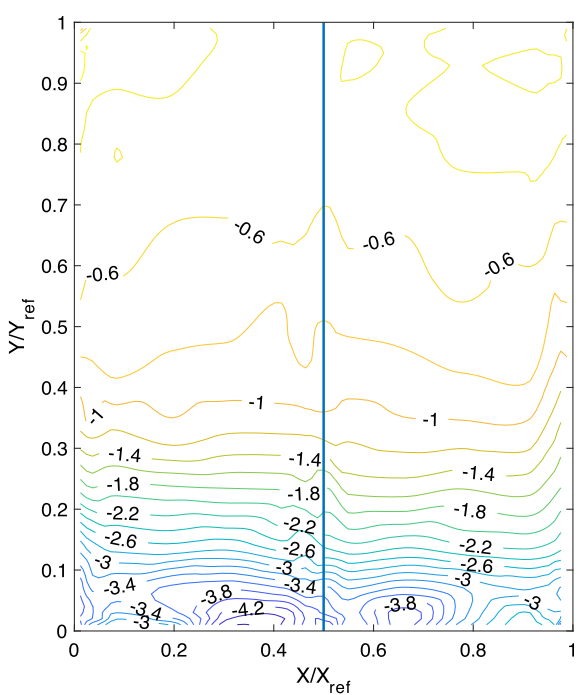

(b)

Fig. 9 Contours of roof pressure coefficients $(\theta=0$ deg.), for the $3 \mathrm{ft}$. parapet case: (a) mean Cps, and (b) 95\% quantile peak Cps 


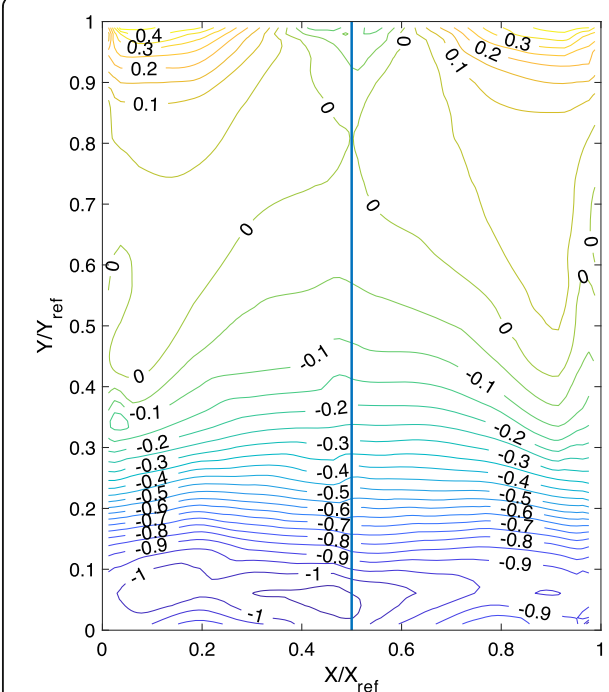

(a)

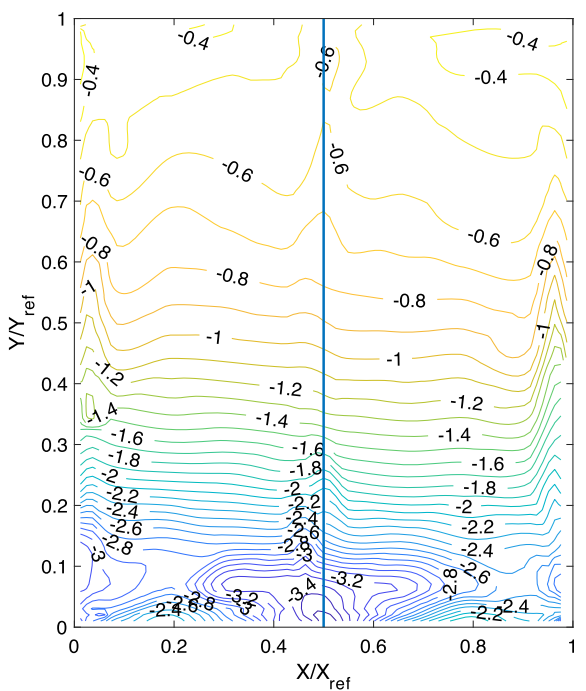

(b)

Fig. 10 Contours of roof pressure coefficients $(\theta=0$ deg.), for the $4.5 \mathrm{ft}$. parapet case: (a) mean Cps, and (b) 95\% quantile peak Cps

compared to laboratory testing. It is also the main reason for the need for aerodynamic testing and the growth of wind tunnel industry that is considered the main source of information for codification. By examining the mean pressure contours, it is noticeable that the addition of any size parapet shortens the length of the separation bubble. In other words, the roof experiences zero and positive pressures that indicate flow reattachment or that shorten length of the separation bubble. The $6 \mathrm{ft}$. parapet demonstrated the greatest reduction in the magnitude of roof pressures. All parapets generally reduce the mean and peak pressures at the corners and push pockets of high negative pressures away from the

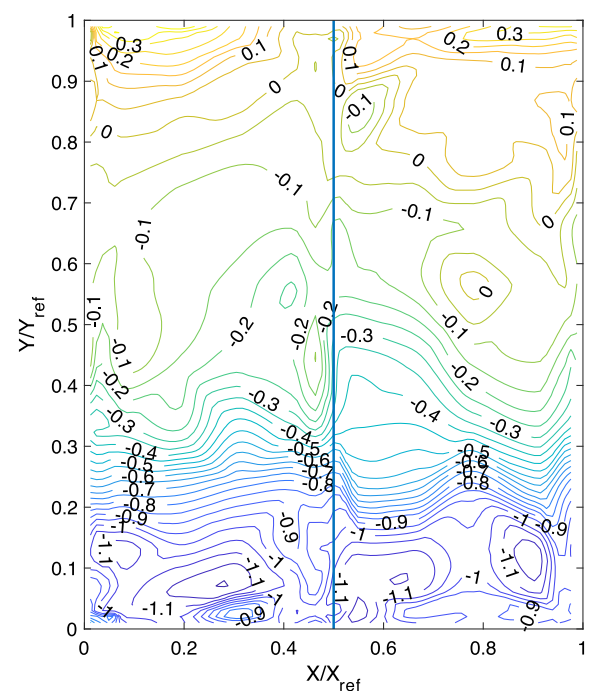

(a)

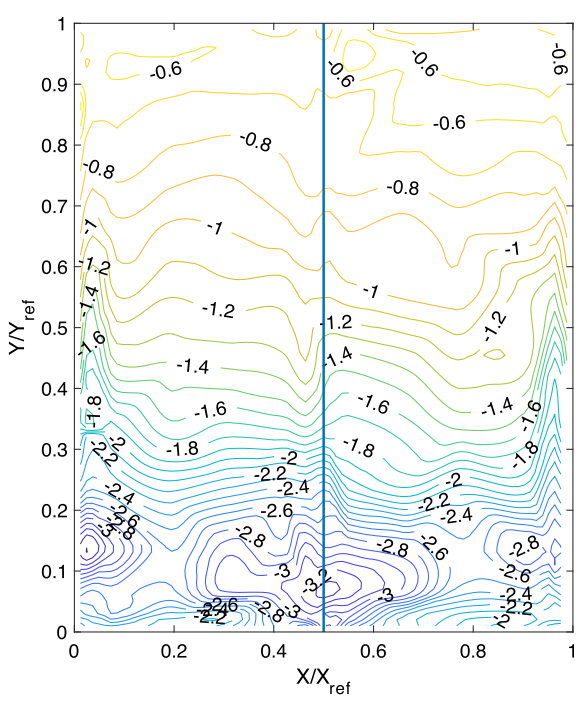

(b)

Fig. 11 Contours of roof pressure coefficients $(\theta=0$ deg.), for the $6 \mathrm{ft}$. parapet case: (a) mean Cps, and (b) 95\% quantile peak Cps 
corners. The $3 \mathrm{ft}$. parapet reduced the windward corner zone mean and peak pressures by approximately $55 \%$ and $60 \%$, respectively. The $4.5 \mathrm{ft}$. parapet yields about $55 \%$ and $65 \%$ reductions in the mean and peak pressures, respectively. No significant additional reductions are seen with the $6 \mathrm{ft}$. parapet, compared to the $4.5 \mathrm{ft}$. parapet. This is similar to the findings of Huang et al. [32] that after a certain height, parapets offer no further reductions in roof pressures. The $6 \mathrm{ft}$. parapet increased the volatility of the entire wind flow which increased the magnitude of mean pressures parallel to the main flow direction. The $6 \mathrm{ft}$. case also increased the magnitude of mean pressures in the corner zones, when compared to the no parapet case and has slightly higher mean pressures in most zones when compared to the other two parapets.

Similarly, Figs. 12, 13, 14 and 15 show the contours of mean and peak pressure coefficients for the scaled model tested at $45 \mathrm{deg}$., for the no parapet case, as well as $3 \mathrm{ft}$., 4.5 $\mathrm{ft}$., and $6 \mathrm{ft}$. equivalent parapets. Similar to the $0 \mathrm{deg}$. wind direction angle, the flow never reattaches in the no parapet case. However, the presence of any parapet causes the flow to reattach on the roof, towards the central zone. Under the $45 \mathrm{deg}$. wind direction angle, the evidence of conical vortices and cornering winds becomes obvious. For the no parapet case, the conical vortices seem to be more constricted and their effects on roof pressures are realizable over a smaller area. Conversely, the higher the parapet, the greater the disruption of the conical vortices. The $3 \mathrm{ft}$. parapet shows a slight reduction in the mean and peak pressures in the corner zones $(20 \%$ and $40 \%$, respectively), and a smaller pocket of negative pressure that develops on the roof ridge. The $4.5 \mathrm{ft}$. and $6 \mathrm{ft}$. parapets show an increase in the magnitude of mean pressures at the corner. The no parapet case showed a higher localized peak pressure, while the parapet cases reduced the magnitude of peak pressures and spread out the vortices causing most taps in the corner to experience higher mean pressures. Consequently, the mean and peak pressures over the inner zones of the roof are increased, especially at the roof's midspan, along the long dimension of the building. All parapets decreased the peak pressures in the

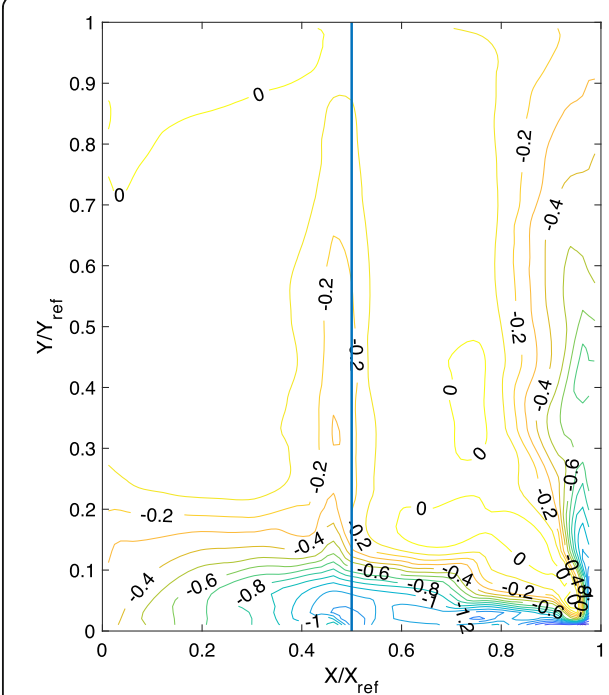

(a)

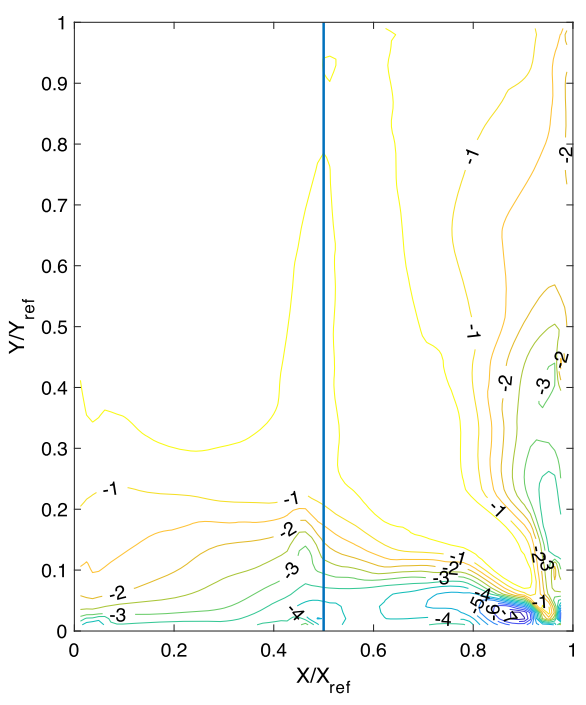

(b)

Fig. 12 Contours of roof pressure coefficients $(\theta=45$ deg.), for the no parapet case: (a) mean Cps, and (a) 95\% quantile peak Cps 


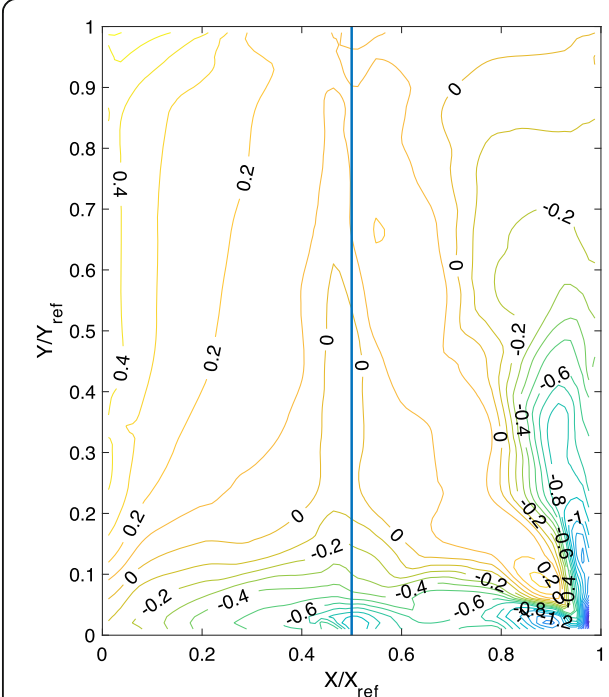

(a)

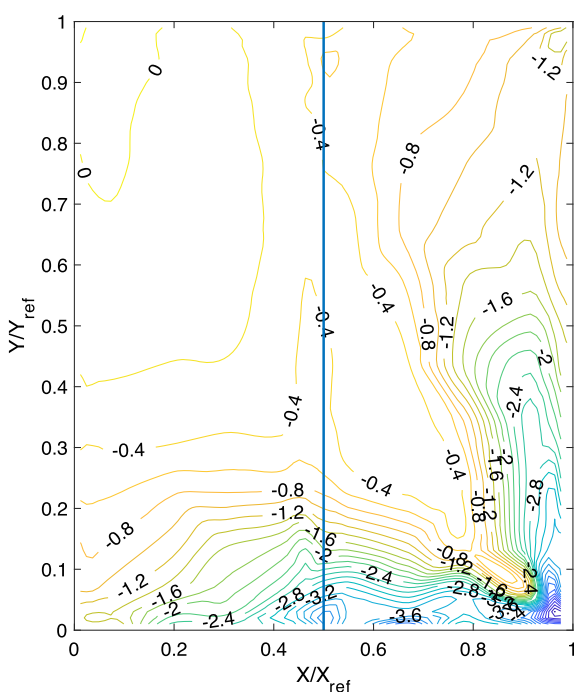

(b)

Fig. 13 Contours of roof pressure coefficients $(\theta=45$ deg.), for the $3 \mathrm{ft}$. parapet case: (a) mean Cps, and (b) 95\% quantile peak Cps

corner zone. Again, no additional reductions in the corner zone pressures were seen when comparing the $6 \mathrm{ft}$. parapet contours to those of the $4.5 \mathrm{ft}$.

Figures 16, 17, 18 and 19 show contour plots of mean and peak pressure coefficients for the scaled model tested under 90 deg. wind direction, for the no parapet case, and $3 \mathrm{ft}$., $4.5 \mathrm{ft}$., and $6 \mathrm{ft}$. equivalent parapets. Similar to the other wind direction angles, the wind flow never reattaches to the roof surface, for the no parapet case. This puts the whole roof under negative uplift forces. The addition of parapets decreased the size of the separation bubble again. In all parapet cases, the magnitude of mean and peak

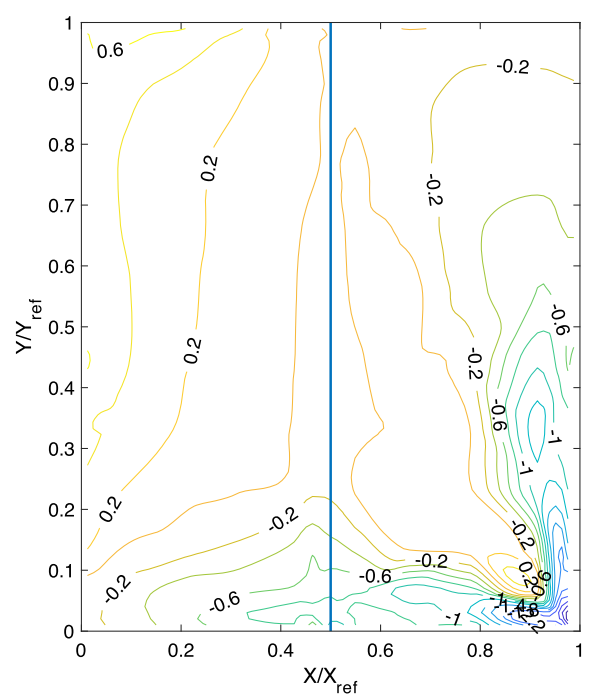

(a)

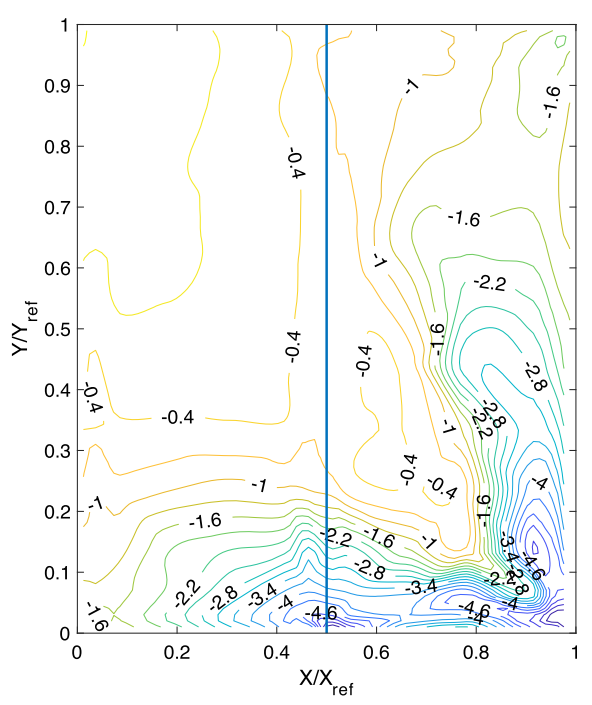

(b)

Fig. 14 Contours of roof pressure coefficients $(\theta=45$ deg.), for the $4.5 \mathrm{ft}$. parapet case: (a) mean Cps, and (b) $95 \%$ quantile peak Cps 


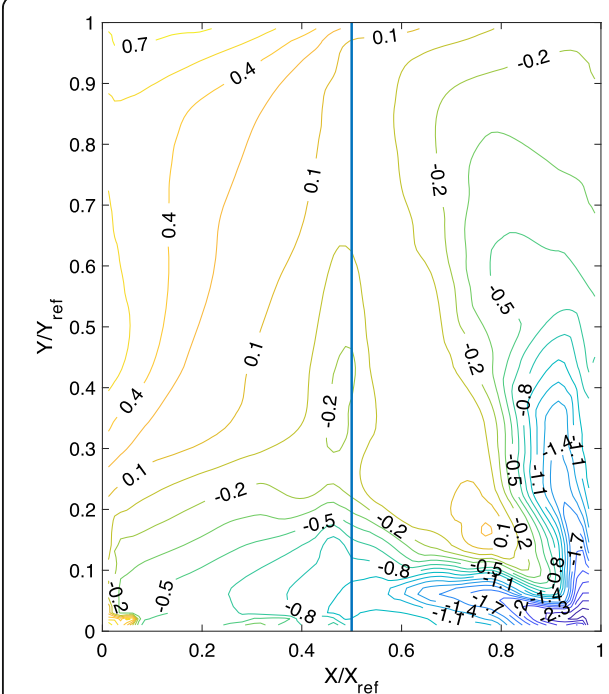

(a)

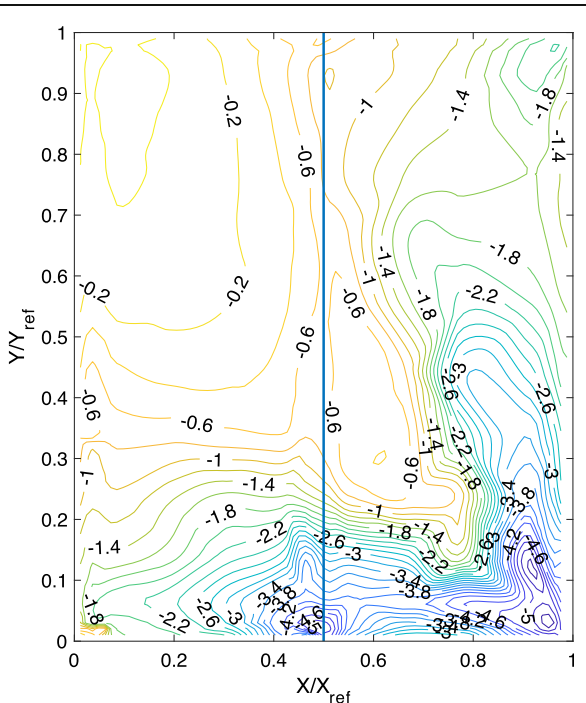

(b)

Fig. 15 Contours of roof pressure coefficients at $(\theta=45$ deg.), for the $6 \mathrm{ft}$. parapet case: (a) mean Cps, and (b) $95 \%$ quantile peak Cps

pressures are reduced at the windward corners. All parapets increased the mean pressure values towards the center of the roof. The $6 \mathrm{ft}$. parapet provides a reduction of approximately $55 \%$ in both mean and peak pressures. The $4.5 \mathrm{ft}$. parapet provides a reduction of about $20 \%$ and $40 \%$ in mean and peak pressures, respectively, parallel to the edges and away from the corners. Contrary to the other wind direction angles, the $6 \mathrm{ft}$. parapet was most efficient in reducing the magnitude of mean and peak pressures in almost all zones. However, the $6 \mathrm{ft}$. parapet increased the mean pressures in the inner zone and the corner zone, the leeward corner zone. The $6 \mathrm{ft}$. parapet increased

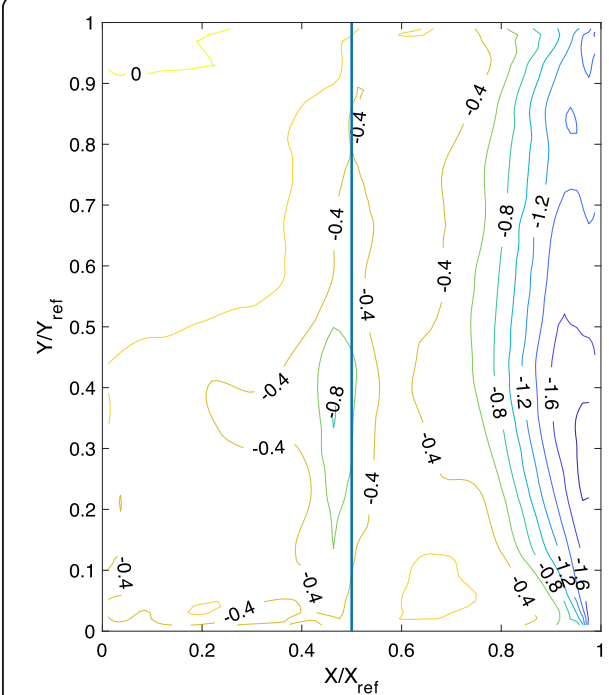

(a)

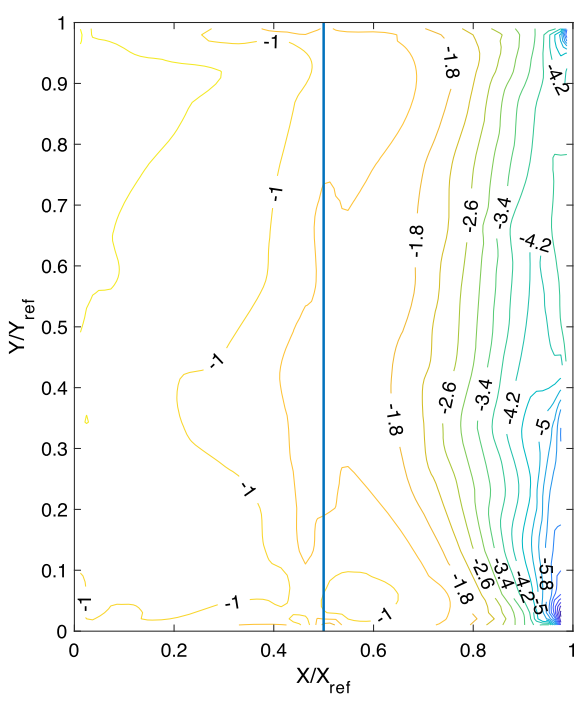

(b)

Fig. 16 Contours of roof pressure coefficients $(\theta=90$ deg.), for the no parapet case: (a) mean Cps, and (a) 95\% quantile peak Cps 


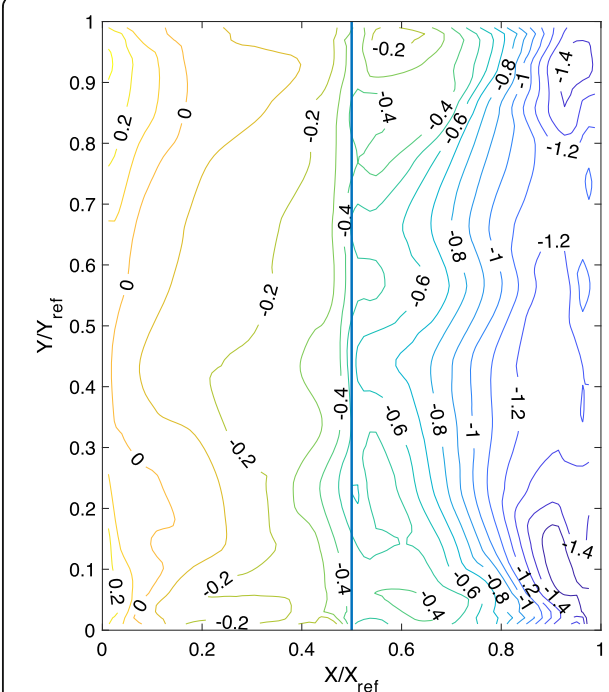

(a)

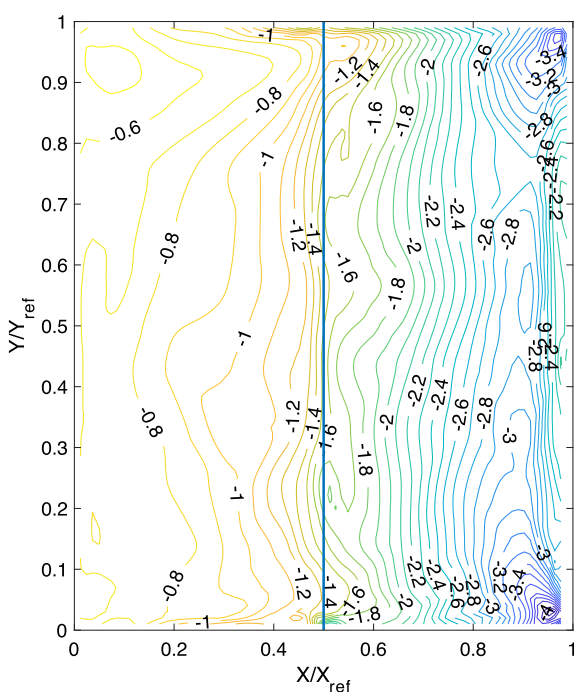

(b)

Fig. 17 Contours of roof pressure coefficients $(\theta=90$ deg.), for the $3 \mathrm{ft}$. parapet case: (a) mean Cps, and (b) 95\% quantile peak Cps

the average pressures the most in the inner zones, followed by the $3 \mathrm{ft}$., and lastly the $4.5 \mathrm{ft}$.

After examining all the pressure contours, it is clear that not one single parapet height worked best for all wind direction angles. The $3 \mathrm{ft}$. parapet is the best in reducing the mean and peak pressure coefficients over all roof zones, under the $45 \mathrm{deg}$. wind direction angle. The $4.5 \mathrm{ft}$. parapet was second most effective followed by the $6 \mathrm{ft}$. parapet. The $3 \mathrm{ft}$. and $4.5 \mathrm{ft}$. parapets are more effective in reducing mean and peak pressures in all zones for the $0 \mathrm{deg}$. and $45 \mathrm{deg}$. wind directions, when compared to the

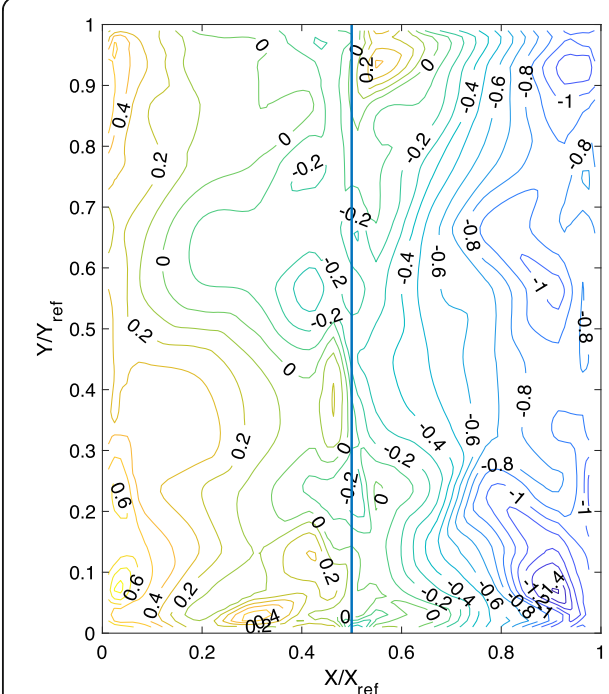

(a)

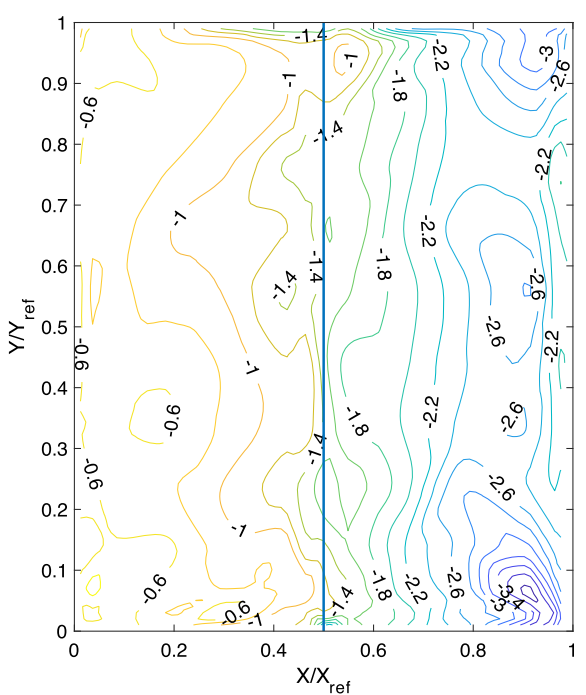

(b)

Fig. 18 Contours of roof pressure coefficients $(\theta=90$ deg.), for the $4.5 \mathrm{ft}$. parapet case: (a) mean Cps, and (b) $95 \%$ quantile peak Cps 


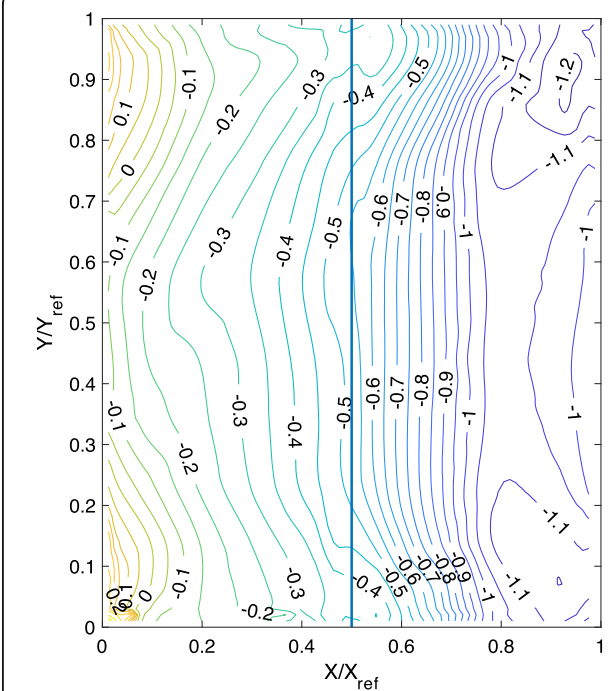

(a)

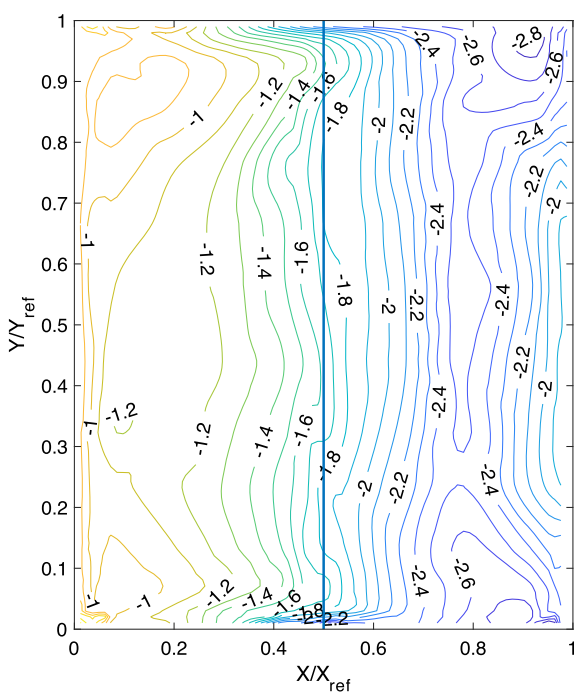

(b)

Fig. 19 Contours of roof pressure coefficients $(\theta=90$ deg.), for the $6 \mathrm{ft}$. parapet case: (a) mean Cps, and (b) 95\% quantile peak Cps

$6 \mathrm{ft}$. parapet. The $6 \mathrm{ft}$. parapet was most effective under the $90 \mathrm{deg}$. wind direction angle.

From these investigations, a $3 \mathrm{ft}$. parapet is deemed most effective at reducing mean and peak pressure coefficients in all zones regardless of the wind direction angle. The height/eave height ratio for the $3 \mathrm{ft}$. parapet is 0.14 , which is in the range that studies on parapet height optimization have concluded to be the best [32]. Similar to other studies, the $6 \mathrm{ft}$. parapet showed relatively no additional benefits over the $4.5 \mathrm{ft}$. parapet. The $6 \mathrm{ft}$. parapet was only more efficient at reducing just the peak pressure coefficients in the zone away from the corners when compared to the $4.5 \mathrm{ft}$. case. This reinforces the fact that after certain height, the effectiveness of parapets plateaus and sometimes is decreased.

\section{Conclusions}

This paper investigated how perimeter solid parapets can alter the flow pattern around a low-rise building by experimentally studying the model in an open-jet hurricane simulator. The importance of the current study is that parapets and other architectural features are difficult to be tested in a typical wall-bounded wind tunnel due to blockage effects and scale issues. We modeled the case study of an actual industrial low-rise building with a large aspect ratio of $\sim 7.6$. The low-rise building has a gable roof with a slope of about $7 \mathrm{deg}$. Solid parapets with varying heights were added to the roof edges and tested in an open-jet wind flow to find the best size of the parapet that minimizes the uplift effects of wind on the roof. We obtained pressure coefficients from data collected in the laboratory, for cases with and without parapets under three wind direction angles $(0,45$, and $90 \mathrm{deg}$.$) . The conclusions are as follows.$

- Implementing a parapet of any size can change the flow pattern around the low-rise building, consequently changing the values of mean and peak pressure coefficients. 
The reduction of the separation bubble length, when a parapet of any size is present, is also realized by comparing the patterns of mean pressures.

- Under the 0 deg. wind direction angle, the $3 \mathrm{ft}$. and $4.5 \mathrm{ft}$. parapets are effective at reducing mean and peak pressures in the corner zones by up to $50 \%$. The $6 \mathrm{ft}$. parapet was not effective in reducing mean pressures at the corners and in some cases caused higher suction when compared to the no parapet case.

- Under the $45 \mathrm{deg}$. wind direction angle, the pressure contours show the formation of conical vortices and cornering winds. The $3 \mathrm{ft}$. parapet was effective at reducing mean and peak pressures in every zone of the roof, including reductions of approximately $20 \%$ and $40 \%$ in the corner zones, respectively. The $4.5 \mathrm{ft}$. and $6 \mathrm{ft}$. parapets increased the magnitude of mean pressures at the corner zones as well as the mean and peak pressures in most of the inner zones of the roof, when compared to the no parapet case.

- Under the 90 deg. wind direction angle, all parapets were efficient at reducing mean and peak corner pressures, with the $6 \mathrm{ft}$. parapet being the most effective. All parapets increased the mean pressures in the roof's innermost zone.

- The $3 \mathrm{ft}$. parapet, which is approximately $14 \%$ of the building's eave height, is the most effective at reducing mean and peak pressures in all roof zones under all wind direction angles considered in the current study.

Acknowledgments

The open-jet simulator used for aerodynamic testing was designed and fabricated by the first author with help from several graduate and undergraduate students at Louisiana State University.

\section{Authors' contributions}

The first two authors contributed equally to the experimental planning, aerodynamic testing, data analysis, and the writing of the paper. The third author helped with aerodynamic testing and some literature review. The authors read and approved the final manuscript.

\section{Funding}

The first author received financial support from the Louisiana Board of Regents (RCS and Enhancement). Also, the first author received funds from the NSF I-Corps program at Louisiana State University. The findings are those of the authors and do not necessarily reflect the position of the funding sponsors.

\section{Availability of data and materials}

The datasets generated during the current study are available from the corresponding author on reasonable request.

\section{Declarations}

\section{Competing interests}

The authors declare that they have no competing interests.

Received: 11 June 2021 Accepted: 21 July 2021

Published online: 09 September 2021

\section{References}

1. Gutnikov VA, Lifanov IK, Setukha AV (2006) Simulation of the aerodynamics of buildings and structures by means of the closed vortex loop method. Fluid Dyn 41(4):555-567. https://doi.org/10.1007/s10697-006-0073-4

2. Khudyakov GE (1968) Aerodynamic characteristics of low-aspect-ratio prismatic bodies near a screen. Fluid Dyn 3(2):7374. https://doi.org/10.1007/BF01013559

3. Bao S, Hu X, Wang J, Ma T, Rao Y, Deng Z (2020) Numerical study on the influence of initial ambient temperature on the aerodynamic heating in the tube train system. Adv Aerodyn 2(1):1-18. https://doi.org/10.1186/s42774-020-00053-8

4. Cheng C, Wu J, Zhang Y, Li H, Zhou C (2020) Aerodynamics and dynamic stability of micro-air-vehicle with four flapping wings in hovering flight. Adv Aerodyn 2:1-19

5. Ke J (2019) RANS and hybrid LES/RANS simulations of flow over a square cylinder. Adv Aerodyn 1(1):1-24. https://doi. org/10.1186/s42774-019-0012-9

6. Shademan M, Naghib-Lahouti A (2020) Effects of aspect ratio and inclination angle on aerodynamic loads of a flat plate. Adv Aerodyn 2(1):1-23. https://doi.org/10.1186/s42774-020-00038-7

7. Shang JJS (2019) Landmarks and new frontiers of computational fluid dynamics. Adv Aerodyn 1(1):1-36. https://doi. org/10.1186/s42774-019-0003-x 
8. National Weather Service (2016) Summary of natural hazard statistics for 2015 in the United States. https://www.wea ther.gov/media/hazstat/sum15.pdf. Accessed 7 Jul 2021

9. Mooneghi MA (2014) Experimental and analytical methodologies for predicting peak loads on building envelopes and roofing systems. Dissertation, Florida International University

10. Lott N, Ross T (2005) Tracking and evaluating US billion dollar weather disasters, 1980-2005. National Oceanic and Atmospheric Administration, U.S. Department of Commerce

11. Baskaran A, Molleti S, Roodvoets D (2007) Understanding low-sloped roofs under hurricane Charley from field to practice. J ASTM Int 4(10):1-13. https://doi.org/10.1520/JAl101055

12. Lin JX, Montpellier PR, Tillman CW, Riker WI, Gx HHM (2008) Aerodynamic devices for mitigation of wind damage risk. In: the 4th international conference on advances in wind and structures (AWAS'08). Pp 1533-1546

13. Magnus JR, Melenberg B, Muris C (2011) Global warming and local dimming: the statistical evidence. J Am Stat Assoc 106(494):452-464. https://doi.org/10.1198/jasa.2011.ap09508

14. Meehl GA, Zwiers F, Evans J, Knutson T, Mearns L, Whetton P (2000) Trends in extreme weather and climate events: issues related to modeling extremes in projections of future climate change. Bull Am Meteorol Soc 81(3):427-436. https://doi.org/10.1175/1520-0477(2000)0812.3.co;2

15. Broach D (2021) These are the 10 most expensive hurricanes in U.S. history; see video, storm tracks. the advocate https:/www.nola.com/news/hurricane/article_cff6f988-9499-11eb-9f35-9387b108dc7f.html. Accessed 7 Jul 2021

16. Strauss BH, Orton PM, Bittermann K, Buchanan MK, Gilford DM, Kopp RE, Kulp S, Massey C, de Moel H, Vinogradov S (2021) Economic damages from hurricane Sandy attributable to sea level rise caused by anthropogenic climate change. Nat Commun 12(1):1-9. https://doi.org/10.1038/s41467-021-22838-1

17. National Oceanic and Atmospheric Administration (2019) Climate change impacts. https://www.noaa.gov/education/ resource-collections/climate/climate-change-impacts. Accessed 7 Jul 2021

18. Lim Y-K, Schubert SD, Kovach R, Molod AM, Pawson S (2018) The roles of climate change and climate variability in the 2017 Atlantic hurricane season. Sci Rep 8(1):1-10. https://doi.org/10.1038/s41598-018-34343-5

19. Samenow J (2017) The forgotten but freakish damage from hurricane Harvey's eyewall in Rockport, Tx. Washington Post https:/www.washingtonpost.com/news/capital-weather-gang/wp/2017/09/01/the-forgotten-but-freakish-damage-fromhurricane-harveys-eyewall-in-rockport-tex/

20. Neuman S (2017) Hurricane Irma leaves devastation of "epic proportions" in Caribbean. NPR, In https://www.npr.org/ sections/thetwo-way/2017/09/07/549136781/devastation-of-epic-proportions-in-caribbean-wake-of-hurricane-irma. Accessed 7 Jul 2021

21. Holmes JD, Sankaran R, Kwok KCS, Syme MJ (1997) Eigenvector modes of fluctuating pressures on low-rise building models. J Wind Eng Ind Aerodyn 69-71:697-707. https://doi.org/10.1016/S0167-6105(97)00198-0

22. Aly AM (2014) Atmospheric boundary-layer simulation for the built environment: past, present and future. Build Environ 75:206-221. https://doi.org/10.1016/j.buildenv.2014.02.004

23. Ho TCE, Surry D, Morrish DP (2003) NIST/TTU cooperative agreement--windstorm mitigation initiative: wind tunne experiments on generic low buildings. BLWT-SS20-2003, boundary-layer wind tunnel laboratory. Univ. of Western Ontario, London

24. Feng R, Liu F, Cai Q, Yang G, Leng J (2018) Field measurements of wind pressure on an open roof during typhoons HaiKui and SuLi. Wind Struct 26:11-24. https://doi.org/10.12989/was.2018.26.1.011

25. Aly AM (2016) On the evaluation of wind loads on solar panels: the scale issue. Sol Energy 135:423-434. https://doi. org/10.1016/j.solener.2016.06.018

26. Aly AM, Gol Zaroudi H (2020) Peak pressures on low rise buildings: CFD with LES versus full scale and wind tunnel measurements. Wind Struct 30:99-117. Doi. https://doi.org/10.12989/was.2020.30.1.099

27. Aly AM, Khaled F, Gol-Zaroudi H (2020) Aerodynamics of low-rise buildings: challenges and recent advances in experimental and computational methods. Aerodynamics, pp 1-22

28. Aly AM, Bitsuamlak G (2013) Aerodynamics of ground-mounted solar panels: test model scale effects. J Wind Eng Ind Aerodyn 123:250-260. https://doi.org/10.1016/j.jweia.2013.07.007

29. Aly AM, Gol-Zaroudi H (2017) Atmospheric boundary layer simulation in a new open-jet facility at LSU: CFD and experimental investigations. Measurement 110:121-133. https://doi.org/10.1016/j.measurement.2017.06.027

30. Gol Zaroudi H, Aly AM (2017) Open-jet boundary-layer processes for aerodynamic testing of low-rise buildings. Wind Struct 25:233-259. Doi: https://doi.org/10.12989/was.2017.25.3.233

31. Aly AM, Yousef N (2021) High Reynolds number aerodynamic testing of a roof with parapet. Eng Struct 234:112006. https://doi.org/10.1016/j.engstruct.2021.112006

32. Huang P, Peng X, Gu M (2017) Wind tunnel study on effects of various parapets on wind load of a flat-roofed low-rise building. Adv Struct Eng 20(12):1907-1919. https://doi.org/10.1177/1369433217700425

33. Suaris W, Irwin P (2010) Effect of roof-edge parapets on mitigating extreme roof suctions. J Wind Eng Ind Aerodyn 98(10-11):483-491. https://doi.org/10.1016/j.jweia.2010.03.001

34. Kopp GA, Mans C, Surry D (2005) Wind effects of parapets on low buildings: part 2. Structural loads. J Wind Eng Ind Aerodyn 93(11):843-855. https://doi.org/10.1016/j.jweia.2005.08.005

35. Kopp GA, Surry D, Mans C (2005) Wind effects of parapets on low buildings: part 1. Basic aerodynamics and local loads. J Wind Eng Ind Aerodyn 93(11):817-841. https://doi.org/10.1016/j.jweia.2005.08.006

36. Mans C, Kopp GA, Surry D (2005) Wind effects of parapets on low buildings: part 3. Parapet loads. J Wind Eng Ind Aerodyn 93(11):857-872. https://doi.org/10.1016/.jweia.2005.08.007

37. Whitbread RE (1963) Wind effects on buildings and structures. Nature 199(4898):1049-1050. https://doi.org/10.1038/1991049a0

38. Holmes JD, Bekele S (2021) Wind loading of structures, 4th edn. CRC Press, Boca Raton

39. Ozmen Y, Baydar E, van Beeck JPAJ (2016) Wind flow over the low-rise building models with gabled roofs having different pitch angles. Build Environ 95:63-74. https://doi.org/10.1016/j.buildenv.2015.09.014

40. Franchini S, Pindado S, Meseguer J, Sanz-Andrés A (2005) A parametric, experimental analysis of conical vortices on curved roofs of low-rise buildings. J Wind Eng Ind Aerodyn 93(8):639-650. https://doi.org/10.1016/j.jweia.2005.07.001

41. Tieleman HW (2003) Wind tunnel simulation of wind loading on low-rise structures: a review. J Wind Eng Ind Aerodyn 91(12-15):1627-1649. https://doi.org/10.1016/j.jweia.2003.09.021 
42. Banks D, Meroney RN, Sarkar PP, Zhao Z, Wu F (2000) Flow visualization of conical vortices on flat roofs with simultaneous surface pressure measurement. J Wind Eng Ind Aerodyn 84(1):65-85. https://doi.org/10.1016/S0167-61 05(99)00044-6

43. Banks D, Meroney RN (2001) A model of roof-top surface pressures produced by conical vortices: evaluation and implications. Wind Struct An Int J 4(4):279-298. https://doi.org/10.12989/was.2001.4.4.279

44. Kawai H, Nishimura G (1996) Characteristics of fluctuating suction and conical vortices on a flat roof in oblique flow. J Wind Eng Ind Aerodyn 60:211-225. https://doi.org/10.1016/0167-6105(96)00035-9

45. Wu F (2000) Full-scale study of conical vortices and their effects near roof corners. ProQuest Dissertations Publishing

46. Surry D, Lin JX (1995) The effect of surroundings and roof corner geometric modifications on roof pressures on low-rise buildings. J Wind Eng Ind Aerodyn 58(1-2):113-138. https://doi.org/10.1016/0167-6105(95)00016-K

47. IBHS (2021) Lead with the Roof. https://ibhs.org/strategy/roof/. Accessed 7 Jul 2021

48. Cochran LS, English EC (1997) Reduction of roof wind loads by architectural features. Archit Sci Rev 40(3):79-87. https:// doi.org/10.1080/00038628.1997.9697388

49. Ahmad S, Kumar K (2002) Effect of geometry on wind pressures on low-rise hip roof buildings. J Wind Eng Ind Aerodyn 90(7):755-779. https://doi.org/10.1016/S0167-6105(02)00152-6

50. Mooneghi MA, Kargarmoakhar R (2016) Aerodynamic mitigation and shape optimization of buildings: review. J Build Eng 6:225-235. https://doi.org/10.1016/j.jobe.2016.01.009

51. Moravej M, Irwin P, Zisis I, Chowdhury AG, Hajra B (2017) Effects of roof height on local pressure and velocity coefficients on building roofs. Eng Struct 150:693-710. https://doi.org/10.1016/j.engstruct.2017.07.083

52. Tominaga $Y$, Akabayashi S, Kitahara T, Arinami $Y$ (2015) Air flow around isolated gable-roof buildings with different roof pitches: wind tunnel experiments and CFD simulations. Build Environ 84:204-213. https://doi.org/10.1016/j.buildenv.2 014.11 .012

53. Huang P, Tao L, Gu M, Quan Y (2014) Wind effects of architectural details on gable-roofed low-rise buildings in southeastern coast of China. Adv Struct Eng 17(11):1551-1565. https://doi.org/10.1260/1369-4332.17.11.1551

54. Bitsuamlak G, Warsido W, Ledesma E, Chowdhury AG (2013) Aerodynamic mitigation of roof and wall corner suctions using simple architectural elements. J Eng Mech 139(3):396-409. https://doi.org/10.1061/(ASCE)EM.1943-7889.0000505

55. Kopp GA, Mans C, Surry D (2005) Wind effects of parapets on low buildings: part 4. Mitigation of corner loads with alternative geometries. J Wind Eng Ind Aerodyn 93(11):873-888. https://doi.org/10.1016/j.jweia.2005.08.004

56. Aly AM, Bresowar J (2016) Aerodynamic mitigation of wind-induced uplift forces on low-rise buildings: a comparative study. J Build Eng 5:267-276. https://doi.org/10.1016/j.jobe.2016.01.007

57. Poitevin A, Natalini B, Godoy LA (2013) Pressures on open canopy structures with parapets under wind loading. Eng Struct 56:850-867. https://doi.org/10.1016/j.engstruct.2013.06.009

58. Turbulent Flow (2015) Geting Started: Series 100 Cobra Probe

59. Turbulent Flow Instrumentation (2021) Products. https://turbulentflow.com.au. Accessed 7 Jul 2021

60. Scanivalve (2021) Intelligent pressure and temperature instrumentation. https://scanivalve.com/\#http://scanivalve.com/a bout-us/. Accessed 7 July 2021

61. Sadek F, Simiu E (2002) Peak non-Gaussian wind effects for database-assisted low-rise building design. J Eng Mech 128(5):530-539. https://doi.org/10.1061/(ASCE)0733-9399(2002)128:5(530)

62. National Institute of Standards and Technology (2011) Special-purpose software: MATLAB functions for estimation of peaks from time series. https://www.itl.nist.gov/div898/winds/peakest_files/peakest.htm. Accessed 7 Jul 2021

\section{Publisher's Note}

Springer Nature remains neutral with regard to jurisdictional claims in published maps and institutional affiliations.

\section{Submit your manuscript to a SpringerOpen ${ }^{\circ}$ journal and benefit from:}

- Convenient online submission

- Rigorous peer review

- Open access: articles freely available online

High visibility within the field

Retaining the copyright to your article

Submit your next manuscript at $\boldsymbol{\nabla}$ springeropen.com 